Revista lus et Praxis, Año 26, № 2, 2020, pp. $320-332$

ISSN 0717 - 2877

Universidad de Talca - Facultad de Ciencias Jurídicas y Sociales

La evolución jurisprudencial del derecho del acusado a la última palabra

Francisco Ortego Pérez

Trabajo recibido el 10 de mayo de 2018 y aprobado el 10 de marzo de 2020

La evolución jurisprudencial del derecho del acusado a la última palabra

THE JURISPRUDENTIAL EVOLUTION OF THE RIGHT OF THE ACCUSED TO THE LAST WORD

Francisco Ortego PÉREZ ${ }^{1}$

RESUMEN

El presente artículo analiza la dimensión que ha adquirido el derecho del acusado a concluir el juicio penal manifestando la última palabra. La interpretación jurisprudencial del proceso penal regulado en la Ley de Enjuiciamiento Criminal española de 1882 ha otorgado un nuevo alcance a este derecho por su conexión con las garantías del debido proceso de ley y el valor del derecho del defensa. Sin embargo, es un derecho que debe ser analizado en función de su efectividad práctica y de su influencia en la sentencia.

ABSTRACT

This article analyzes the dimension acquired by the right of the accused to conclude the criminal trial by manifesting the final say. The jurisprudential interpretation of the criminal process regulated in the Spanish Criminal Procedure Act of 1882 has granted a new scope to this right by its connection with the guarantees of due process of law and the value of the right of defense. However, it is a right that must be analyzed for its practical effectiveness and its influence on the sentence.

PALABRAS CLAVE

Derecho a la última palabra, principio de contradicción, derecho de defensa.

KEY WORDS

Right to the last word, principle of contradiction, right of defense.

\title{
1. Exordio
}

En el proceso penal español, llegando al colofón de la vista oral no debería pasar desapercibida, como en la mayoría de las ocasiones acaba sucediendo en la práctica, la significación procesal que puede deparar el derecho a la última palabra del acusado. Es uno de los trámites más fugaces de la LECrim, circunstancia que no por ello empece ni rebaja su alcance procesal dado las consecuencias prácticas que se derivan de su hipotética inobservancia por parte del juzgador. Cuestión distinta es la de su grado de influencia en la sentencia.

Pese a estar regulado ya originariamente en la Ley de Enjuiciamiento Criminal (LECrim) desde 1882, este derecho ha ido adquiriendo una nueva significación procesal gracias a la interpretación garantista realizada en la jurisprudencia desde las últimas décadas del siglo pasado. Por ello no deja de resultar paradójico que pese a su visibilidad legal tradicionalmente haya sido considerado como una actuación prescindible, y en consecuencia, «invisible» en el terreno práctico, debido a los consejos por parte de los abogados defensores instando a los acusados a no decir nada nuevo, para evitar incurrir

\footnotetext{
${ }^{1}$ Profesor Titular de Derecho Procesal, Universidad de Barcelona, Barcelona, España. Correo electrónico: fortego@ub.edu.
} 
en riesgos inesperados ante el más que previsible temor de que esa singular declaración pueda acabar desbaratando toda la estrategia defensiva.

Bastaría con el ejemplo de un conocido caso ocurrido en España en 1994 y que acaparó buena parte de la atención pública por lo horrendo de aquel crimen para comprender esos hipotéticos riesgos. Fue denominado como "el crimen del rol", en el que los dos acusados, tratando de escenificar un juego de rol en vivo cuyas reglas habían sido previamente ideadas por uno de ellos, salieron una noche en busca de una persona de características determinadas con el único propósito de asesinarla de un modo especialmente macabro.

Como refiere la STS núm. 632/1998 de 25 de junio, el procesado como autor intelectual de aquel crimen, que se había acogido previamente a su derecho a no declarar en la vista oral y había negado su participación en la instrucción de la causa, sorprendió al mostrar su voluntad de hacer uso de su última palabra, desmontando la tesis de los forenses respecto a cómo y quién pudo asestar determinadas puñaladas mortales, lo que a supuso reconocer abiertamente su autoría en detrimento de su propia defensa.

Desde el punto de vista del descubrimiento de la verdad material los riesgos que pueden implicar la última declaración son evidentes, pero tampoco debe olvidarse que se configura como el ejercicio de un derecho, y que puede resultar especialmente válido en determinados casos, como en las causas juzgadas por el Tribunal del Jurado. De ahí la oportunidad de realizar unas consideraciones acerca de este derecho y del aparente antagonismo existente entre la realidad práctica y la exégesis jurisprudencial.

\section{Las diversas consideraciones en torno al derecho a la última palabra: de un trámite rituario a un derecho efectivo}

En la dinámica del juicio penal se encuentra ese efímero momento después de practicadas las pruebas y de los informes de acusación y defensa. Tras el mismo el proceso será declarado ya concluso y visto para sentencia, por lo que a priori no resultaría descabellado llegar a pensar, parafraseando a Julio César antes de cruzar el Rubicón, que para el acusado "alea iacta est". Y sin embargo, tal como refieren algunas Sentencias del Tribunal Supremo, se trata de "un momento de especial importancia", pues el procedimiento aun dispensa una última garantía en ese instante final ${ }^{3}$, por cuanto el art. 739 LECrim establece que será entonces cuando "el Presidente preguntará a los procesados si tienen algo que manifestar al Tribunal", de forma que "al que contestare afirmativamente le será concedida la palabra".

Pero también debe subrayarse que su propia ubicación procedimental, unida a la trascendencia de la prueba como elemento determinante sobre el que formar la convicción del juzgador y al carácter potestativo de su ejercicio por el acusado, propiciaron que en épocas pasadas la finalidad del derecho a la última palabra no siempre fuera bien ponderada.

La doctrina lo contempló como un derecho escasamente efectivo ${ }^{4}$ ya que confería una intervención más teórica que práctica, pues podía verse notablemente limitada tanto por la actuación del propio Abogado defensor como por la actitud de algunos presidentes de Sala, que con frecuencia reputaban innecesario dicho trámite 5 . Incluso alguna sentencia refleja este parecer al considerarlo "un

\footnotetext{
${ }^{2}$ Tal y como lo conciben la SSTS núm. 843/2001 de 10 de mayo, [R. J. 2001/9952], núm. 556/2000 de 5 de abril, [R. J. 2000/1445] y la SAP de Segovia núm. 79/2002 de 26 de septiembre, [JUR 2002/273689].

${ }^{3}$ AGUILERA (1924), p. 555.

${ }^{4} \mathrm{O}$ un "derecho más espectacular que real" en palabras de FENECH (1952), p. 114.

${ }^{5}$ SERRA (1969a), p. 782 y SERRA (1971), p. 219. Asimismo, véase SERRA (1969b) p. 697 y SERRA (1965), p. 99. Este es un argumento que
} 
trámite muy tardío y escasamente determinante, que se produce cuando el juicio prácticamente ha terminado" (STS núm. 259/2015 de 30 de abril [R. J. 2015/1720]).

No es de extrañar que otras resoluciones de los tribunales recuerden expresamente cómo durante años su consideración se redujo a la de un mero rito o simple formalidad procesal "sin mayor trascendencia sobre la validez del juicio oral"6, pues "se trata de una cláusula estereotipada que no puede faltar y así figura en los impresos utilizados en las actas de los juicios orales"7.

Estas circunstancias han propiciado que también en la doctrina más reciente sea considerado un «derecho absurdo» y carente de sentido en el proceso penal acusatorio.

Así, en opinión de Nieva Fenoll, únicamente tendría una verdadera justificación en el antiguo procedimiento inquisitivo, en el que no se escuchaba al reo salvo para obligarle mediante coacciones o el uso del tormento para arrancar su confesión, pero sin conferirle ninguna otra forma de participación adicional en el proceso. En cambio, conservar en la actualidad el derecho del acusado a una última palabra cuando ya ha tenido otras oportunidades a lo largo del juicio para declarar cuanto quisiese es la razón por la que la institución está en desuso. A ello hay que añadir las precauciones de los letrados defensores ante esos ya mencionados riesgos que pueden tirar por tierra todo el trabajo de la defensa.

En otras ocasiones simplemente es aprovechado como un momento de exaltación histriónica por parte del acusado que en nada contribuye a la finalidad del juicio. Son razones por las que, a juicio de este autor, este anacrónico derecho debería ser abolido, pues no es más que la pervivencia de una manifestación inquisitiva en la propia LECrim ${ }^{8}$.

Sin embargo, la aplicación de las garantías que dimanan de la Constitución Española de 1978 al proceso penal de la centenaria LECrim, unida a la hermenéutica llevada a cabo por la jurisprudencia del Tribunal Constitucional ${ }^{9}$, ha otorgado a algunos derechos una dimensión hasta entonces desconocida. Tal es el caso del derecho regulado en el art. 739 LECrim, pues el incuestionable interés legítimo de cualquier acusado por concluir el proceso con un alegato en su propio beneficio enlaza con el desarrollo de un proceso con todas las garantías, por lo que lejos de quedar desdibujado se realza su valor en pos de una defensa efectiva.

Desde la óptica del proceso justo (due process of law) se evidencia la distancia existente entre aquella vieja concepción de la última palabra del acusado como un simple trámite rituario sin apenas incidencia procesal y su actual consideración como un derecho, que, en el caso de resultar vulnerado, produce una manifiesta situación de indefensión por resultar lesivo respecto al derecho de defensa ${ }^{10}$. Sin que tradicionalmente hubiera suscitado un especial interés entre la doctrina, ha sido la jurisprudencia la que ha corregido aquella percepción inicial y ensalzado el alcance procesal de dicho trámite. No obstante, su importancia debe ponderarse en su justa medida para evitar una sobrevaloración alejada de la realidad práctica, pues, aunque su configuración como derecho instrumental del de defensa resulta incuestionable, en términos de efectividad la mayoría de las veces

\footnotetext{
comparte hoy CORTÉS Y MORENO (2017), p. 464.

${ }^{6}$ STS núm. 566/2000 de 5 de abril [R.J. 2000/1445].

${ }^{7}$ STS de 12 de noviembre de 1991 [R.J. 1991/8061].

${ }^{8}$ NIEVA (2019), pp. 13-14.

${ }^{9}$ RAMOS (2016a), pp. 26, 27 y en toda la obra citada.

${ }^{10}$ Como establece la STS núm. 849/2003 de 9 de junio [R. J. 2003/7159], "este último trámite del plenario no puede ser suprimido sin lesionar gravemente el derecho fundamental a la defensa que garantiza a todos el art. 24.2 CE. [...] El derecho reconocido al acusado en el art. 739 LECrim se inscribe plenamente en el derecho de defensa, por lo que privar al mismo de la posibilidad de decir la última palabra en el proceso penal debe ser considerado lesivo de dicho derecho fundamental y motivo suficiente para casar y anular la Sentencia que se haya dictado tras producirse tal infracción constitucional". Por su parte, la STS núm. 209/2008 de 28 de abril [R. J. 2008/2183], recuerda el firme criterio de la jurisprudencia del Tribunal Supremo "en orden al cumplimiento de tal trámite procesal, atribuyendo la importancia que nuestra Constitución y los Convenios Internacionales suscritos por España le conceden en orden a una completa y adecuada defensa del inculpado".
} 
suele presentar poca influencia en la decisión final del juicio. De ahí que en realidad presenta una mayor significación procesal por su consideración garantista conectado a las exigencias del debido proceso que por la repercusión real de lo que el acusado pudiera llegar a manifestar.

Ahora bien, lejos de verse hoy como una mera formalidad, nuestros tribunales reconocen que lo que el art. 739 de la LECrim brinda al acusado es la oportunidad final de ratificarse o rectificar sus anteriores declaraciones, las de los coimputados en la causa o las realizadas por los testigos, así como la posibilidad de discrepar de su defensa técnica o completarla de alguna manera, de suerte que "la viva voz del acusado es un elemento personalísimo y esencial para su defensa en juicio"11.

\section{La interpretación jurisprudencial del derecho del acusado a la última palabra}

Esa interpretación de signo garantista iniciada en la última década del siglo pasado por la jurisprudencia constitucional y seguida luego por la Sala Segunda del Tribunal Supremo, ha perfilado el alcance y contenido del derecho a la última palabra ${ }^{12}$.

En esa línea, en la actualidad cabe sintetizar como los rasgos más característicos de este derecho los siguientes: $a$ ) es una consecuencia derivada del principio de audiencia y contradicción; $b$ ) forma parte integrante del contenido mismo del derecho de defensa; $c$ ) es un derecho de carácter personalísimo y potestativo para el acusado, pero necesariamente preceptivo para el órgano jurisdiccional; $y d$ ) es un derecho susceptible de restricción legal.

A estas consideraciones hay que añadir las repercusiones procesales del derecho examinado.

\subsection{Su vínculo con el principio de contradicción}

Desde la STC 181/1994 de 20 de junio, primer pronunciamiento destacado del Tribunal Constitucional en esta materia, se afirma que el derecho a la última palabra hunde sus raíces en el principio de que nadie puede resultar condenado sin haber sido previamente oído y vencido en juicio, configurador de una de las garantías procesales más primarias ${ }^{13}$ (nemo inauditus damnari potest). Cabe recordar que el principio de audiencia o contradicción debe entenderse como un mandato dirigido al legislador para que la regulación de los distintos procesos sea respetuosa con el derecho de defensa, ya que uno de los más claros supuestos de indefensión que puede causarse a una parte es precisamente privarle de la oportunidad de ser escuchado ${ }^{14}$.

Una consolidada doctrina jurisprudencial recuerda que una vez establecido ese diseño legal "corresponde a los órganos judiciales velar por que en las distintas fases de todo proceso se dé la necesaria contradicción entre las partes", haciendo posible el ejercicio del derecho de defensa. Este deber se agudiza de manera muy significativa en el proceso penal debido a la especial trascendencia de los intereses en juego, por lo que es preciso asegurar "el respeto del derecho de defensa del imputado más allá del mero respeto formal de las reglas procesales".

Teniendo en cuenta estas premisas, posibilitar la contradicción se erige en "una de las reglas

\footnotetext{
${ }^{11}$ Así se pronuncian entre otras las SSTC 181/1994 de 20 de junio [F.J. 3], 29/1995 de 6 de febrero [F.J. 6], 109/2002 de 6 de mayo [F.J. 3], 93/2005 de 18 de abril [F.J. 3], 13/2006 de 16 de enero [F.J. 4], 258/2007 de 18 de diciembre [F.J. 2]. En idéntico sentido vid. las SSTS núm. 566/2000 de 5 de abril [R.J. 2000/1445], núm. 745/2004 de 10 de junio [R.J. 2005/2159], núm. 835/2007 de 23 de octubre [R.J. 2007/7315]. E igualmente lo hacen las Sentencias de las Audiencias Provinciales de: Madrid (Sección 6a), núm. 191/2015 de 13 de marzo [JUR 2015/96857] y Toledo (Sección 1a), núm. 39/2016 de 18 de febrero [JUR 2016/63629].

${ }^{12}$ En idéntico sentido véase BELLIDO (2012), p. 78. OCAÑA (2013), pp. 198-204. ADÁN (2013), pp. 529-541; del mismo autor véase ADÁN (2017), pp. 134-137.

${ }^{13}$ RAMOS (2016b), p. 382.

${ }^{14}$ MONTERO (1997), p. 145. BERZOSA (1992), pp. 563-564.
} 
esenciales del desarrollo del proceso, sin cuya concurrencia [...] la idea del juicio justo es una simple quimera"15, por lo que el derecho de todo acusado a ser oído en juicio en defensa de sus propios intereses constituye una garantía esencial del proceso penal acusatorio ${ }^{16}$.

Esto explica que a lo largo de la causa se establezcan diversos momentos para escuchar al sujeto pasivo, siendo uno de los mismos el trámite de «audiencia personal» previsto en el art. 739 LECrim, que como último acto del plenario supone "la más completa materialización del derecho a que nadie pueda ser condenado sin ser oído"17. Por su significación garantista incluso se propugna que esta genuina expresión del principio de contradicción debería instaurarse también al final de la vista en los recursos de apelación y de casación, al estilo de lo previsto en el § 351. 2 de la StPO alemana ${ }^{18}$.

\subsection{La última palabra como genuina manifestación de la autodefensa}

Su vínculo con el principio de contradicción sitúa al derecho a la última palabra como una manifestación inequívoca y pura de la autodefensa.

En la legislación procesal española prevalece el derecho de asistencia letrada, lo que supone que la propia defensa queda ciertamente minimizada debido a la tecnificación de la justicia. Algunos autores ya pusieron de relieve esta regulación residual de la autodefensa en el proceso penal, sin que en su parecer estuviera justificado que tal circunstancia obedeciese al hipotético riesgo que comportaría la asunción por el propio acusado de tan importante derecho ${ }^{19}$.

Precisamente uno de los escasos supuestos legales en los que se admite su ejercicio es el regulado en el art. 739 LECrim, junto con otras manifestaciones reconocidas durante la etapa de instrucción, como son la posibilidad de declarar cuantas veces lo solicite (art. 400 LECrim) o la de oponerse personalmente al auto que eleva la detención a prisión provisional (art. 501 LECrim).

Este papel secundario de la autodefensa en juicio ha sido una constante histórica, pues por mucho que la denominada defensa privada constituya una aspiración legítima de cualquier acusado, la defensa técnica prevalece como consecuencia del modelo de postulación y de la complejidad intrínseca al proceso.

A modo de ejemplo histórico MOMMSEN explica que el procedimiento penal romano durante la última etapa de la república no concedía a las partes el derecho de pronunciar discursos finales, pues aquella era una función atribuida a sus defensores, si bien durante la práctica de la prueba al acusado no se le prohibía, como muestra primaria de autodefensa, que pudiera asentir o negar lo que le pareciera oportuno ${ }^{20}$.

En la actualidad el derecho de todo acusado a defenderse por sí mismo tiene reconocimiento legal expreso en el art. 6.3 c) del C.E.D.H. y en el art. 14.3 d) del P.I.D.C.P., mientras que la C.E. proclama en su art. 24.2 el derecho "a la defensa y a la asistencia de letrado".

No obstante, la jurisprudencia declara de forma reiterada que el derecho de defensa comprende tanto la defensa técnica ejercida mediante abogado de libre elección o por designa de

\footnotetext{
${ }^{15}$ Sobre la vinculación del principio de contradicción con el derecho a un proceso con todas las garantías véanse entre otras las SSTC 65/2007 de 27 de marzo [F. J 2], 12/2006 de 16 de enero [F.J. 3], 13/2006 de 16 de enero [F.J. 4], 93/2005 de 18 de abril [F.J. 3], 91/2000 de 30 de marzo [F.J. 13], 138/1999, de 22 de julio [F.J. 4], 122/1995 de 18 de julio [F.J. 2].

${ }^{16}$ SSTC 12/2006 de 16 de enero [F.J. 3], 93/2005 de 18 de abril [F.J. 3], 143/2001 de 18 de junio [F.J. 3], 144/1007, de 15 de septiembre [F.J. 4] y STS 669/2006 de 14 de junio [2006/4759].

${ }_{17}$ STS núm. 843/2001 de 10 de mayo [R. J. 2001/9952].

${ }^{18}$ GIMENO (2017), p. 8. Del mismo autor véase GIMENO (2012), pp. 1 y 7; GIMENO (2015), p. 829.

${ }_{19}$ SERRA (1969b), p. 696. GUTIÉRREZ-ALVIZ (1953), p. 773. MORENO (1982), p. 33.

${ }^{20} \mathrm{Y}$ recuerda que en una inusual alteración del orden procedimental en el juicio seguido contra Milón por el asesinato de Clodio -célebre por el alegato defensivo pronunciado por Cicerón en su discurso pro Milone - las partes sí que pronunciaron sus discursos finales después de practicada la prueba. MOMMSEN (1905), pp. 415 y 417.
} 
oficio, como la posibilidad de defenderse personalmente "en la medida en que lo regulen las Leyes procesales de cada país"21.

En esa remisión a los respectivos ordenamientos internos, el derecho comparado ofrece diversos ejemplos de cómo el acusado puede concluir el juicio haciendo uso de su última palabra (tal como puede verse en el $\S 258$ StPO alemana, art. 346 Code de Procédure Pénale francés, art. 361.1 Código de Processo Penal portugués, o en el art. 523.5 Codice di Procedura penale italiano) ${ }^{22}$.

Por su parte, la LECrim establece en su art. 739 una garantía de audiencia que, aunque mínima, no puede reducirse en ningún caso a ser una mera invitación protocolaria mediante la clásica pregunta realizada por el Juez o el presidente del Tribunal.

Al tratarse de una garantía con sustantividad propia el derecho a la última palabra debe diferenciarse del derecho a la asistencia letrada, hasta el punto de que ha de poder ser ejercido autónomamente al margen de aquel, otorgándole el valor que por sí mismo le corresponde ${ }^{23}$, pues supone "una de las manifestaciones más genuinas de la autodefensa"24.

Sin embargo, aunque no esté expresamente proclamado como garantía del proceso justo ${ }^{25} \mathrm{su}$ pertenencia al mismo resulta incuestionable, por lo que este derecho resulta aplicable a todos los procesos penales por delito, lo que incluye a la categoría de los delitos leves ${ }^{26}$ y hace igualmente extensiva su utilización al proceso penal de menores, en el que presenta una variante específica (art. 37. 2 de la L. O. 5/2000 de 12 de enero) $)^{27}$ que corrobora que se trata de una garantía que no puede faltar por la trascendencia del derecho al que aparece vinculado.

\subsection{Naturaleza del derecho a la última palabra}

Este trámite de audiencia material faculta a todo acusado, ya sea persona física o jurídica (art. 786 bis 1 LECrim) para ejercer un derecho personalísimo y potestativo, que sin embargo puede ser restringido legalmente en determinadas circunstancias.

a) Se trata de un derecho de carácter personal, por el que como inequívoca manifestación de la autodefensa se le reconoce al acusado la oportunidad de expresar directamente cuantas alegaciones estime que puedan contribuir al ejercicio y reforzamiento de ese derecho, permitiéndole "suministrar al Tribunal elementos dignos de advertencia y reflexión que los

\footnotetext{
${ }^{21}$ SSTC 181/1994, de 2 de junio [F.J. 3], 11/1997, de 27 de enero [F.J. Único], 13/2006 de 16 de enero [F.J. 4], 258/2007, de 18 de diciembre [F.J. 2]. Respecto al reconocimiento del derecho de autodefensa véase asimismo la STEDH de 25 de abril de 1983, Caso Pakelli c. Alemania [TEDH 48].

${ }^{22} \mathrm{El} \S 258$ (3) StPO dispone: "Der Angeklagte ist, auch wenn ein Verteidiger für ihn gesprochen hat, zu befragen, ob er selbst noch etwas zu seiner Verteidigung anzuführen habe" (Se preguntará al acusado, incluso cuando el defensor hubiera hablado por él, si todavía tiene que indicar él mismo algo en su defensa". El art. 346 Code de procédure pénale en el inciso final de su tercer apartado dispone que "...l'accusé ou son avocat auront toujours la parole les derniers". Por su parte, el art. 361.1 Código de Processo Penal establece que "Findas as alegaçoes, o presidente pregunta ao arguido se tem mais alguma coisa a alegar em sua defesa, ouvindo-o em tudo o que declarar a bem dela", mientras que el art. 523.5 Codice di Procedura penale establece que "In ogni caso, l'imputato e il difensore devono avere, a pena di nulità, la parola per ultimi se la domandano".

${ }^{23}$ SSTC $181 / 1994$ de 20 de junio [F.J. 3], 13/2006 de 16 de enero [F.J. 4].

${ }^{24}$ STS núm. 835/2007 de 23 de octubre [R. J. 2007/7315].

${ }^{25}$ STS núm. 1075/1996 de 26 de diciembre [R. J. 1996/9652].

${ }^{26}$ La jurisprudencia menor ya había reconocido que dicho trámite "es de aplicación mutatis mutandis a los procedimientos por faltas", categoría de ilícitos que tras la reforma del Código Penal por la L.O. 1/2015 de 30 de marzo ha dado paso a la de delitos leves. Entre otras véase la SAP de Barcelona (Sección 7ạ) de 6 de mayo de 2002 [JUR 2002/181160], SAP de Valencia (Sección 4ạ) de 28 de mayo de 1999 [ARP 1999/1971] y la SAP de Zaragoza (Sección 3a) de 26 de enero de 2000 [ARP 2000/5].

${ }^{27}$ Dispone el citado precepto que, tras la práctica de la prueba y después de que el Juez oiga al Ministerio Fiscal, a quien hubiere ejercitado la acción penal, al letrado del menor, al actor civil y a los terceros responsables respecto a los derechos que les asisten, al equipo técnico y, en su caso, a la entidad pública de protección de menores, en último término "el Juez oirá al menor, dejando el expediente visto para sentencia". Véase también la STC 13/2006 de 16 de enero [F.J. 4] y la STS núm. 835/2007 de 23 de octubre [R. J. 2007/7315]. E igualmente véase PORTAL (2018), p. 15.
} 
defensores hubieren omitido"28.

Su ejercicio no solo permite integrar las posibles omisiones de su defensa técnica, pues si bien es cierto que en otras épocas se consideró que facultaba al acusado para alegar las circunstancias que no hubieran sido ya puestas de relieve en el informe de su defensor ${ }^{29}$, hoy se contempla con tal amplitud que, con independencia del contenido de dicho informe, el acusado podrá ratificarlo, rectificarlo o contradecirlo en uso de esa postrer manifestación, pues en consonancia con su cualidad procesal "el juicio comienza y termina dando la palabra a los acusados" (STS núm. 259/2015 de 30 de abril [R. J. 2015/1720]).

La posibilidad legal de realizar esta alegación final incluso ha sido considerada como un privilegio concedido al acusado que rompería la igualdad de armas en el plenario ${ }^{30}$, aunque como acertadamente reconoce la jurisprudencia, el turno de última palabra no supone quebranto alguno de dicho principio, sino que es una manifestación que responde al "«status» diferente y más favorable" del que goza el acusado respecto al acusador en pos de garantizar mejor su defensa ${ }^{31}$.

b) Es un derecho potestativo para el acusado y a la vez constituye una obligación legal para el juzgador, pues solo se ejercitará cuando aquel manifieste su deseo de usar la palabra en respuesta a la preceptiva pregunta del presidente del Tribunal.

Con independencia de que los procesados opten por ejercerlo o no, el juzgador debe favorecer su cumplimiento en todo caso, pues como establece la STS núm. 843/2001 de 10 de mayo [R. J. 2001/9952], aunque en la práctica es frecuente que los acusados renuncien a este derecho, ello no obsta a que el Tribunal deba promover su ejercicio, bajo sanción en caso contrario de declaración de la nulidad del juicio oral y la consiguiente retroacción de las actuaciones al momento inicial de dicha fase ${ }^{32}$.

En consonancia con su finalidad teleológica de reforzar el derecho de defensa, algún lejano comentarista de la LECrim ya apuntaba que esta invitación legal del art. 739 debía ser cumplida de manera escrupulosa y fidelísima por parte del Tribunal, sin impedimentos ni recomendaciones que de facto convirtieran en ilusorio uno de los derechos más preciados que la ley otorga a los acusados ${ }^{33}$.

c) Es un derecho que puede verse limitado ope legis. La obligación del Tribunal de garantizar su ejercicio no es óbice para que pueda restringirlo, ya que "su utilización debe realizarse en términos razonables y admisibles" (STS núm. 566/2000 de 5 de abril). Por este motivo la LECrim prevé su restricción cuando el trámite sea indebidamente aprovechado por los procesados de forma que al ejercer su derecho ofendan a la moral o falten al respeto debido al Tribunal o a las consideraciones correspondientes a todas las personas, retirándoles la palabra tras las oportunas admoniciones en caso necesario ${ }^{34}$.

Constituye una obviedad que la manifestación de la última palabra se vincula al derecho del

\footnotetext{
${ }^{28}$ STS núm. 1786/2002 de 28 de octubre [R. J. 2002/9998] y núm. 891/2004 de 13 de julio [R. J. /4127].

${ }^{29}$ GUTIÉRREZ-ALVIZ (1953), p. 796.

${ }^{30}$ TRILLO (2007), p. 1814.

${ }^{31}$ STS núm. 843/2001 de 10 de mayo [R. J. 2001/9952] y SAP de Segovia núm. 79/2002 de 26 de septiembre [JUR 2002/273689]. En la doctrina ADÁN (2017), p. 135, lo considera "una discriminación positiva" en torno a su figura, aunque respetuosa con la igualdad de partes.

${ }^{32}$ STS 849/2003 de 9 de junio [R. J. 2003/7159]. Véase asimismo la STS núm. 1683/2001 de 25 de septiembre [R. J. 2001/9601], en la que no se consideró vulneración del derecho la no constancia en el acta del juicio oral de lo manifestado por el acusado en dicho trámite, puesto que lo que sí constaba era la invitación realizada por el Tribunal en tal sentido.

${ }^{33}$ AGUILERA (1924), p. 555.

${ }^{34}$ Como recoge la SAP de A Coruña (Sección 2a) núm. 345/2009 de 7 de septiembre [ARP 2009/1213], en la que la retirada de la palabra al acusado se debió a que pretendía entablar discusión con los intervinientes en el juicio, "lo que no es admisible ni puede quedar amparado dentro del contenido de tal derecho". Distinto es el supuesto de la SAN (Sala de lo penal, Sección 2ä) de 24 de abril de 2008 [ARP 2008/218], que declaró la vulneración del derecho de defensa producido en el juicio celebrado ante el Juzgado Central de lo Penal durante el que no se concedió a los acusados el derecho a la última palabra por expresarse estos en catalán, teniéndoles el juzgador como si hubieran guardado silencio a pesar de la realidad de sus manifestaciones.
} 
acusado a estar presente en la vista oral, lo que a su vez es otra manifestación del genérico derecho de defensa. De ahí que más allá de la mera retirada de la palabra, y siendo su presencia física en el plenario el presupuesto ineludible para poder ejercer este derecho ${ }^{35}$, hay que tener en cuenta la posible expulsión del acusado de la Sala por alteración del orden con una conducta procesal inconveniente u obstruccionista.

En tal caso la Ley faculta al Juez o al presidente del Tribunal para que en el ejercicio de sus prerrogativas de dirección de los debates pueda acordar que "sea expulsado por cierto tiempo o por toda la duración de las sesiones, continuando éstas en su ausencia" (art. 687 LECrim).

Pero incluso en esos supuestos el juzgador deberá permitirle regresar para que pueda ejercer, si lo desea, el derecho a la última palabra ${ }^{36}$, pues está obligado a compatibilizar el mantenimiento del orden en la Sala con la necesaria observancia de este trámite para que no se produzca merma alguna en el derecho de defensa (STS núm. 843/2001 de 10 de mayo y SAP de Valencia [Sección 2ạ], núm. 710/2009 de 18 de noviembre [JUR 2010/187770]) $)^{37}$.

\subsection{Contenido del derecho a la última palabra}

Este trámite de audiencia material "posee un contenido y cometido propio y bien definido" dentro del derecho de defensa (SSTC 13/2006, de 16 de enero, [FF. JJ. 4 y 5] y 258/2007 de 18 de diciembre [F.J. 2]), que puede desglosarse en los siguientes aspectos:

a) La ratio de esta intervención conclusiva del plenario estriba en que es precisamente el acusado quien conoce mejor que nadie todas las vicisitudes respecto a los hechos que constituyen el objeto del enjuiciamiento y sobre los que se sustenta la base de la acusación. De ahí que, según una consolidada jurisprudencia, este alegato es "una especie de resumen o compendio de todo lo que ha sucedido en el debate público y contradictorio que constituye la esencia del juicio oral" 38 , máxime si se tiene en cuenta que antes ya ha podido realizar otras declaraciones. Sin embargo, a pesar de la amplitud con la que pueda usarse esta finalidad sintética o de precisión, el borrador de Código Procesal Penal de 2013 ceñía su ejercicio a "la necesidad de no reiterar los argumentos ya expuestos por el letrado de la defensa" (art. 469.1).

b) Constituye el colofón del proceso penal, de manera que lo manifestado entonces no puede

\footnotetext{
${ }^{35}$ SSTC 29/1995 de 6 de febrero [F.J. 3 y 6], 91/2000 de 30 de marzo [F.J. 13], la última de las cuales subraya la importancia de garantizar la autodefensa en el plenario, estableciendo que "La vista oral no es una simple secuencia del proceso penal, sino el momento decisivo" del mismo. Consecuentemente, el derecho del acusado a estar presente en la vista oral no solo es una consecuencia del principio de contradicción, sino la forma de garantizar su autodefensa y de que pueda así ejercer, entre otros, su derecho a la última palabra [F.J. 13]. En parecidos términos se manifiesta la STS de 16 de julio de 1984 [R. J. 1984/4208] cuando afirma que la presencia del acusado en el acto del juicio oral deviene "indispensable para que presencie todos los actos procesales constitutivos de su enjuiciamiento y [...] por último, para que pueda ejercer el derecho denominado "de última palabra»", y la STS núm. 209/2008, de 28 de abril [R. J. 2008/2183].

${ }^{36}$ La SAP de Sevilla (Sección 1á) núm. 611/2004 de 28 de diciembre [JUR 2005/141628] acuerda la nulidad de un juicio inmediato de faltas por la expulsión del denunciado de la Sala privándole de este modo del derecho a la última palabra y vulnerando así su derecho de defensa. Por su parte, la STS núm. 355/2014 de 14 de abril [R. J. 2014/2620], en un caso en el que la acusada que había sido expulsada tras varias advertencias previas por interrumpir el normal desarrollo del juicio, consideró que al no volver voluntariamente a la Sala cuando el presidente del Tribunal le ordenó que lo hiciera tras el informe de la defensa, "puede entenderse que renunció a su derecho" a la última palabra.

${ }^{37}$ En sentido contrario se manifiesta ASENCIO (2017), p. 105, para quien en tal caso no existe obligación por parte del Tribunal de invitar al acusado a entrar de nuevo en la Sala para ofrecerle el turno de palabra del art. 739 LECrim, pues la falta de realización material de esta última manifestación estaría compensada por su dirección letrada.

${ }^{38}$ Entre otras muchas pueden verse las SSTC 13/2006 de 16 de enero [F.J. 4], 258/2007 de 18 de diciembre [F.J. 2], las SSTS núm. 566/2000 de 5 de abril [R.J. 2000/1445], STS 849/2003 de 9 de junio [R. J. 2003/7159], STS 669/2006 de 14 de junio [R. J. 2006/4759], núm. 209/2008 de 28 de abril [R. J. 2008/2183], 825/2009 de 16 de julio [R. J. 2010/1989], núm. 355/2014 de 14 de abril [R. J. 2014/2620], la SAN (Sala de lo penal, Sección 2ä) de 24 de abril de 2008 [ARP 2008/218], la SAP de Asturias (Sección 2å) núm. 187/2008 de 6 de noviembre [JUR 2009/134132], SAP de Madrid (Sección 6ạ) núm. 106/2011 de 12 de abril [JUR 2011/198964] y la SAP de Santa Cruz de Tenerife núm. 451/2011 de 29 de julio [JUR 2012/13734].
} 
ser sometido a un nuevo debate por las partes, ya que en caso contrario "lo dicho por el acusado dejaría de ser la última palabra para convertirse en una más de sus declaraciones ante el Tribunal"39.

Se trata de garantizar que lo último que escuche el juzgador antes de dictar sentencia "sean precisamente las manifestaciones del propio acusado, que en ese momento asume personalmente su defensa" (STC 13/2006), proporcionándole "la oportunidad de contradecir o someter a contraste todo el proceso probatorio", ya que en el momento previsto para su declaración inicial desconoce cómo se va a desarrollar la práctica de la prueba y las líneas argumentales de la acusación y puede que hasta las de su propia defensa ${ }^{40}$.

Algunas sentencias inciden en que su distinción con la declaración prestada durante la práctica de la prueba (impropiamente denominada en la ley confesión de los procesados), no solo estriba en el momento en el que ambas se producen, sino que el auténtico criterio diferencial entre una y otra es su finalidad, pues mientras que el interrogatorio se concibe como una declaración de descargo frente a la acusación, la oportunidad procesal que dispensa el art. 739 LECrim sirve para corregir cualquier olvido o para ratificar, adicionar o matizar hechos o afirmaciones realizados durante el juicio ${ }^{41}$.

Su propia finalidad impide cualquier otra manifestación que no se circunscriba al uso adecuado de la palabra, por lo que este trámite no puede dar cobertura a actuaciones como la aportación o exhibición de objetos o de partes del cuerpo del propio acusado, al tratarse de actuaciones consideradas como "una clara extralimitación del derecho" (STS núm. 1786/2002 de 28 de octubre, [R. J. 2002/9998]).

\subsection{La lesión del derecho y su consecuencia procesales}

Al ser la última palabra del acusado una manifestación de la autodefensa la jurisprudencia reconoce unánimemente que "este último trámite del plenario no puede ser suprimido sin lesionar gravemente el derecho fundamental a la defensa"42.

Como sostiene la SAP de Granada núm. 16/2004 de 17 de enero [JUR 2004/61513], todos los actos procesales que en la vista oral tienen como protagonista al acusado adquieren una evidente relevancia, por lo que la ausencia del ofrecimiento por parte del Tribunal para ejercer este último turno de palabra debe reflejarse necesariamente en el acta del juicio oral, debido a la «especial trascendencia» que produce su omisión respecto al derecho de defensa.

Por esa "especial trascendencia» del derecho fundamental afectado, cuando se omita su ejercicio ni tan siquiera será preciso que el abogado del acusado haya de formular protesta para que se entienda producida la lesión, pues la vigencia del derecho de defensa no puede condicionarse a una especial diligencia reclamatoria de su letrado (SSTS núm. 1515/1997 de 9 de diciembre, 849/2003 de 9 de junio [2003/7159], 891/2004 de 13 de julio [R. J. 2004/4127] y STC 13/2006 de 16 de enero [F.J. 5]).

La lesión en un derecho fundamental del acusado implica como consecuencia jurídica la nulidad de pleno derecho cuando se haya producido indefensión por prescindirse de las normas esenciales del procedimiento (art. 238. 3 L.O.P.J.). Consecuentemente, la vulneración del derecho regulado en el art. 739 LECrim conducirá como regla general a la nulidad del plenario, con la obligación de repetir el juicio en su integridad con nuevos magistrados no contaminados para salvaguardar la

\footnotetext{
${ }^{39}$ Véase STC 13/2006 de 16 de enero [F.J. 4], STS núm. 960/2007 de 29 de noviembre [R. J. 2008/781] y la STSJ de Andalucía (Granada) núm. 5/1999 de 6 de marzo [ARP 1999/3034].

${ }^{40}$ SSTS núm. 566/2000 de 5 de abril [R.J. 2000/1445] y núm. 825/2009 de 16 de julio [R. J. 2010/1989].

${ }^{41}$ SSTS núm. 1075/1996 de 26 de diciembre [R. J. 1996/9652], núm. 554/2000 de 27 de marzo [R. J. 2000/3481] y núm. 825/2009 de 16 de julio [R. J. 2010/1989].

42 SSTS núm. 1515/1997 de 9 de diciembre [R. J. 1997/8938], núm. 566/2000 de 5 de abril [R. J. 2000/ 1445] y núm. 849/2003 de 9 de junio [2003/7159].
} 
imparcialidad objetiva exigible a todo órgano jurisdiccional ${ }^{43}$.

Ahora bien, el Tribunal Construccional introdujo un considerable matiz respecto al drástico efecto que supone declarar la nulidad del juicio, al exigir que, pese a su indudable conexión con el derecho de defensa, en el recurso de amparo no solo debe alegarse el incumplimiento formal de dicho trámite, sino fundamentalmente la indefensión material que la lesión del derecho hubiera producido al acusado. De esta forma, no todos los casos en que se incumpla el ofrecimiento al acusado de la última palabra acarrearán necesariamente la nulidad de actuaciones por indefensión, sino que será preciso acreditar que el trámite omitido hubiera resultado decisivo para poder determinar un contenido distinto del fallo.

La consecuencia directa de la nulidad de actuaciones del juicio oral queda mitigada así mediante el establecimiento de la carga para el recurrente en amparo de tener que acreditar subjetivamente "la repercusión efectiva que su pleno ejercicio hubiera producido" (STC 13/2006 de 16 de enero [F.J. 5] y 258/2007 de 18 de diciembre [F.J. 3]), exponiendo qué concreta actividad probatoria o qué alegaciones pretendía contradecir o matizar mediante esta última oportunidad procesal de ser escuchado ${ }^{44}$.

\section{Acerca de su efectividad: última palabra del acusado y convicción judicial}

Más allá de la consideración garantista de este derecho por su vínculo con el de defensa, es necesario analizar este trámite en términos de eficacia procesal, pues no se trata de valorar únicamente los efectos de su omisión, sino también la repercusión que lo manifestado por el acusado pueda tener en el fallo del juzgador, tal como expuse supra y da cuenta la STS núm. 259/2015 de 30 de abril [R. J. 2015/1720].

Téngase en cuenta que su finalidad primordial es la de ofrecer una última oportunidad para realizar alegaciones de precisión frente a las tesis acusatorias y poder influir de este modo en la decisión final del tribunal ${ }^{45}$.

Aunque la jurisprudencia sostiene que este derecho "es algo más que una invitación protocolaria de carácter epilogar" (SSTS núm. 835/2007 de 23 de octubre [R.J. 2007/7315] y 209/2008 de 28 de abril [R. J. 2008/2183]), lo cierto es que el margen de maniobra de este turno de palabra parece reducirlo de facto al de un auténtico epílogo del juicio, una suerte de apostilla verbal dada la imposibilidad de abrir nuevos turnos de réplica una vez ejercitado el mismo.

Para evitar su reducción al de un derecho más efectista que efectivo ${ }^{46}$ hay que valorar el grado de influencia de lo alegado por el acusado para formar la convicción judicial, por lo que más allá de las habituales tesis exculpatorias, cabe cuestionarse cuál es la incidencia de una confesión de culpabilidad que realizada en ese momento aportase los elementos mínimos para enervar la presunción de inocencia.

\footnotetext{
${ }^{43}$ SSTS núm. 1515/1997 de 9 de diciembre [R. J. 1997/8938], núm. 566/2000 de 5 de abril [R. J. 2000/ 1445], núm. 866/2002 de 16 de mayo [R. J. 2002/6382], SAP de Granada (Sección 1ạ) núm. 16/2004 de 17 de enero [JUR 2004/61513], SAP de Madrid (Sección 6a) núm. 191/2015 de 13 de marzo [JUR 2015/96857], SAP de León (Sección 3ą) núm. 173/2017 de 18 de abril [JUR 2017/131884], SAP de Santa Cruz de Tenerife núm. 451/2011 de 29 de julio [JUR 2012/13734].

${ }^{44}$ MAGRO (2009b), pp. 707-708; MAGRO (2009a), p. 5. Por otra parte, esta carga de alegación se considera como un frágil argumento, pues es difícil adivinar el contenido que hubiera tenido la sentencia de haberse permitido la manifestación del acusado. RIVERO (2015), p. 3.

${ }^{45}$ FAVAROTTO (2016), pp. 37 y ss. Véase del mismo autor FAVAROTTO (s.f.).

${ }^{46}$ Para MARTíN (2014), p. 89, cualquier manifestación que realice el acusado en este trámite ha de ser tenida en cuenta, aunque lo considera un acto de carácter «más bien simbólico». Y para CORTÉS Y MORENO (2017), p. 464, "es más espectacular que otra cosa», pues el hecho de estar normalmente mediatizado o cercenado por la defensa del acusado le hace perder buena parte de su eficacia, cuando no toda.
} 
En una hipervaloración de dicho trámite ciertas opiniones abogan por atribuir a la última palabra un valor de "prueba material" con el que dotarlo de verdadero contenido, lo que permitiría que las manifestaciones del acusado pudieran ser tenidas en cuenta para formar la convicción del Tribunal y una sentencia de condena, pues pese a no ser en rigor un acto formal de prueba realizado con la debida inmediación, el hecho de que el juicio concluya concediendo la palabra al acusado para matizar, completar o rectificar lo que considere conveniente le confiere un amplísimo margen de actuación hasta el punto de poder ser valorado libremente por el Tribunal ${ }^{47}$.

Ahora bien, aunque el juicio concluye con este acto tras el que no están permitidos otros turnos de palabra, el principio de apreciación en conciencia ya se extiende a "lo manifestado por los mismos procesados" durante el juicio, tal como expresamente dispone el art. 741 LECrim.

Al respecto, la jurisprudencia establece que nada se opone a que una oportunidad concedida en pos de la autodefensa del acusado pueda ser "aprovechada por éste para reconocer los hechos o para aportar datos que puedan ser tenidos en cuenta en su contra, pues se trata de una declaración prestada libremente y con todas las garantías", lo que permite que lo manifestado en el ejercicio de su última palabra pueda ser tenido en cuenta como elemento de convicción ${ }^{48}$, aunque como afirma categóricamente la STSJ de Andalucía núm. 5/1999 de 6 de marzo, "el derecho a la última palabra del acusado no está previsto legalmente como una prueba más a practicar en el juicio oral".

Más allá de un valor probatorio del que realmente carece, lo que permite este trámite es que el Tribunal incorpore a los elementos de juicio que habrán de ser objeto de valoración lo manifestado por el acusado, para apreciarlo conjuntamente en conciencia conforme al art. $741 \mathrm{LECrim}^{49}$, aunque lo manifestado no tiene porqué ser necesariamente aceptado dada la soberana libertad valorativa que corresponde al Tribunal (STS núm. 889/2000 de 8 de junio [R. J. 200176433]).

\section{BIBLIOGRAFÍA CITADA}

ADÁN DOMÈNECH, FEDERIC (2013): “El derecho a la última palabra: configuración jurisprudencial”, en: Picó i Junoy, Joan (Dir.), Principios y garantías procesales (Barcelona, Bosch), pp. 529-542.

(2017): "El derecho a la última palabra: análisis de su aplicación judicial”, en: Fuentes Soriano, O. (Coord.), El proceso penal. Cuestiones fundamentales (Valencia, Ed. Tirant lo Blanch), pp. 133-142.

AGUILERA DE PAZ, ENRIQUE (1924): Comentarios a la Ley de Enjuiciamiento Criminal (Madrid, Ed. Reus), tomo V.

ASENCIO GALLEGO, JOSÉ MARÍA (2017): Juicio oral en la Ley de Enjuiciamiento Criminal española (Lisboa, Ed. Juruá).

BELLIDO PENADÉS, RAFAEL (2012): Derecho de defensa y principio acusatorio en el juicio de faltas: evolución jurisprudencial y análisis crítico (Madrid, Ed. Dykinson).

BERZOSA FRANCOS, VICTORIA (1992): “Principios del proceso”, en: Justicia (Año 1992, № III), pp. 553-620.

${ }^{47}$ TRILLO (2007), pp. 1814-1821. En parecidos términos respecto a su valor, RIVERO (2015), p. 3.

48 SSTS núm. 1031/2003 de 8 de septiembre [R. J. 2003/ 6352], núm. 2188/2002 de 26 de diciembre [R. J. 2003/553], núm. 1179/2001 de 20 de julio [R. J. 2001/4945].

${ }^{49}$ SSTS núm. 866/2002 de 16 de mayo [R. J. 2002/6382], núm. 1786/2002 de 28 de octubre [R. J. 2002/9998], núm. 891/2004 de 13 de julio [R. J. 2004/4127], SAP de Guipúzcoa (Sección 1a) núm. 2/2007 de 8 de enero [JUR 2007/122590]. 
CORTÉS DOMÍNGUEZ, VALENTín Y MORENO CATENA, VÍctoR (2017): Derecho Procesal Penal, 8ae edición (Valencia, Ed. Tirant lo Blanch).

FAVAROTTO, RICARDO (2016): "El derecho a la última palabra", en: Revista de Derecho Penal y Criminología (Año VI, № 7), pp. 37-44.

(S.F.): "El derecho a la última palabra", en: Red de Jueces penales de la provincia de Buenos Aires. Disponible en: http://reddejueces.com/?p=4764 [visitado el 10 de mayo de 2018].

feneCh NAVARRO, Miguel (1952): Derecho Procesal Penal (Barcelona, Ed. Labor), tomo I.

GIMENO SENDRA, VICENTE (2012): “El derecho fundamental a un proceso acusatorio", en: Diario La Ley (№ 7869).

(2015): Derecho Procesal penal, 2ª edición (Madrid, Ed. Civitas-Thomson).

(2017): “El nuevo recurso de apelación ante los T.S.J. y A.N.”, en: Diario La Ley (№ 8988).

GUTIÉRREZ-ALVIZ Y CONRADI, FAUSTINO (1953): “Aspectos del derecho de defensa en el proceso penal”, en: Revista de Derecho Procesal Iberoamericana (Año 1953, IV).

MAGRO SERVET, VICENTE (2009a): "De nuevo sobre el derecho a la última palabra ante la reforma de la LECrim y el contenido del acta del juicio oral”, en: La Ley penal (№ 60, mayo 2009).

(2009b): Guía de problemas prácticos y soluciones del juicio oral (Madrid, Ed. La Ley).

MARTíN OSTOS, JOSÉ (2014): “El juicio oral en el proceso penal”, en: Justicia (№ 2), pp. 69-90.

MOMMSEN, THEODOR (1905): El Derecho penal romano (Traducc. P. Dorado, Madrid, La España Moderna).

MONTERO AROCA, JUAN (1907): Principios del proceso penal. Una explicación basada en la razón (Valencia, Ed. Tirant lo Blanch).

MORENO CATENA, VÍctOR (1982): La defensa en el proceso penal (Madrid, Ed. Civitas).

NIEVA FENOLL, JORDI (2019): “La instrucción como falsa «primera instancia» del proceso penal: hacia una total superación del sistema inquisitivo”, en: Revista Ítalo-Española de Derecho Procesal (Vol. 1), pp. $1-18$.

OCAÑA ESCOLAR, LUIS (2013): "La última palabra: aproximación a un mecanismo de autodefensa jurídica", en: Lex Social. Revista Jurídica de los Derechos Sociales (Vol. 3, № 2), pp. 194-205.

PORTAL MANRUBIA, JOSÉ (2018): “El fortalecimiento de las garantías procesales en la jurisdicción penal de menores", en: Revista Aranzadi Doctrinal (№ 4). 
RAMOS MÉNDEZ, FRANCISCO (2016a): Enjuiciamiento Criminal. Duodécima lectura constitucional (Barcelona, Ed. Atelier).

(2016b): El sistema procesal español, 10ae edición (Barcelona, Ed. Atelier).

RIVERO ORTIZ, R. (2015): “¿El derecho a la última palabra afecta a la presunción de inocencia?”, en: Diario La Ley (№ 8454).

SERRA DOMínguez, MANUEL (1965): "El imputado", en: Nueva Enciclopedia Jurídica (Barcelona, Ed. Seix), tomo XII.

(1969a): “El juicio oral”, en: Estudios de Derecho Procesal (Barcelona, Ed. Ariel). (1969b): “El imputado”, en: Estudios de Derecho Procesal (Barcelona, Ed. Ariel).

(1971): “El juicio oral”, en: Nueva Enciclopedia Jurídica (Barcelona, Ed. Seix), tomo XIV.

TRILLO NAVARRO, JESÚS (2007): “El derecho a la última palabra: prueba material”, en: Diario La Ley (№ 6693). 